This document is the Submitted Manuscript version of a Published Work that appeared in final form in Carbon, copyright (C) Elsevier Ltd. after peer review and technical editing by the publisher.

To access the final edited and published work see

http://ac.els-cdn.com/S0008622313006441/1-s2.0-S0008622313006441-

main.pdf? tid=572d1180-7e90-11e3-8153-

$\underline{00000 a a b 0 f 27 \& a c d n a t=1389864595 \_6533998 \mathrm{e} 0 \mathrm{ca} 8 \mathrm{c} 0026 \mathrm{~d} 3 \mathrm{f} 28304 \mathrm{~d} 0 \mathrm{e} 0 \mathrm{a} 01}$

\title{
Enhanced electron transfer in composite films of reduced graphene oxide and $\operatorname{poly}(\mathrm{N}$ -
}

\section{methylaniline)}

Tom Lindfors $^{1, *}$, Anna Österholm ${ }^{1, \dagger}$, Jussi Kauppila $^{2}$ and Róbert E. Gyurcsányi ${ }^{3}$

${ }^{1}$ Åbo Akademi University, Process Chemistry Centre, Department of Chemical Engineering, Laboratory of Analytical Chemistry, FI-20500 Turku, Finland

${ }^{2}$ University of Turku, Turku University Centre for Materials and Surfaces (MATSURF), Laboratory of Materials Chemistry and Chemical Analysis, FI-20014 Turku, Finland

${ }^{3}$ Budapest University of Technology and Economics, Department of Inorganic and Analytical Chemistry and Research Group of Technical Analytical Chemistry of the Hungarian Academy of Sciences, H-1111 Budapest, Szt. Gellért tér 4, Hungary

Poly $(N$-methylaniline) (PNMA) has been electropolymerized for the first time from a graphene oxide (GO) dispersion containing $1.0 \mathrm{M} \mathrm{HClO}_{4}$. Both $\mathrm{GO}$ and perchlorate were incorporated in the PNMA matrix during the electropolymerization resulting in the formation of a mixed composite material of $\mathrm{PNMA}^{-\mathrm{ClO}_{4}}$ and PNMA-GO. Under the acidic polymerization conditions, the carboxylic groups of GO are undissociated and GO is therefore mostly mechanically entrapped in the PNMA matrix while perchlorate functions as the primary charge compensating ion. Electrochemical reduction at $-0.85 \mathrm{~V}$ improved the electron transfer of the composite film due to reduction of GO in the PNMA matrix.

\footnotetext{
* Corresponding author. Tel: +358 2 2154419. E-mail address: Tom.Lindfors@ abo.fi (T. Lindfors)

${ }^{\dagger}$ Current address: Georgia Institute of Technology, School of Chemistry and Biochemistry, Atlanta, GA, USA
} 
Polyaniline (PANI) is one of the most studied electrically conducting polymers (ECP) due to its good environmental stability, easy and cost-effective synthesis, and high electrical conductivity at acidic $\mathrm{pH}$ [1]. However, PANI is usually deprotonated at slightly acidic and neutral $\mathrm{pH}$ resulting in the loss of the conductivity [2]. This property excludes the use of PANI in in vitro applications operating at physiological $\mathrm{pH}$. It can be overcome by using $\operatorname{poly}(\mathrm{N}$ alkylanilines) (PNANI) which maintain their electroactivity even at neutral pH [3]. Despite of their low pH sensitivity $[2,4]$, the PNANIs have been studied to much lesser extent than PANI due to their lower electrical conductivity [5]. The incorporation of graphene or reduced graphene oxide (rGO) into PNANI films is expected to improve their electrical conductivity and mechanical properties. We have recently reported a simple electrochemical method by which 3,4-ethylenedioxythiophene (EDOT) was first electropolymerized in the presence of graphene oxide (GO) as the only dopant [6]. The GO in the composite film of poly(3,4ethylenedioxythiophene) and GO was then electrochemical reduced to rGO [7]. The successful reduction was confirmed by X-ray photoelectron spectroscopy (XPS). Here we report the electropolymerization of $\mathrm{N}$-methylaniline (NMA) from a $\mathrm{GO}$ dispersion containing $\mathrm{HClO}_{4}$. We show that the electrochemical reduction of GO in the poly( $N$-methylaniline) (PNMA) matrix improved the electron transfer in the composite matrix due to the rGO formation.

The electropolymerization of NMA was carried out with cyclic voltammetry between $0.2 \mathrm{~V}$ and $0.85 \mathrm{~V}$ from a GO dispersion (4.4. $\mathrm{mg} / \mathrm{l}$ ) containing $0.1 \mathrm{M} \mathrm{NMA}$ and $1.0 \mathrm{M} \mathrm{HClO}_{4}$ (Fig. 1a). Before starting the potential cycling, the electropolymerization was initiated by a potential pulse $(10 \mathrm{~s})$ at $0.85 \mathrm{~V}$. The synthesis of the GO dispersion has been reported elsewhere [6]. The cyclic voltammograms $(\mathrm{CV})$ recorded during the electropolymerization of 0.1 M NMA in 1.0 $\mathrm{M} \mathrm{HClO}_{4}$, in the absence of $\mathrm{GO}$ (not shown), are almost similar to the $\mathrm{CVs}$ in Fig. 1a. This indicates that the electrically non-conducting GO does not participate as a charge compensating counter ion to any considerable extent in the PNMA film growth. The PNMA films electropolymerized in the presence and absence of GO were characterized in monomer- 
free 1.0 $\mathrm{M} \mathrm{HClO}_{4}$ (Fig. 1b). The CVs of the two PNMA films have almost identical oxidation and reduction behavior suggesting that GO is mostly mechanically entrapped in the PNMA matrix with perchlorate functioning as the primary charge compensating counter ion. Under the acidic polymerization conditions, the carboxylic groups of GO are undissociated (uncharged) further supporting the assumption that GO is mostly mechanically entrapped in the PNMA matrix during the electropolymerization. The scanning electron microscopy (SEM) images in Fig. 2 verify that a mixed composite material was formed consisting of domains of PNMA-GO and $\mathrm{PNMA}_{-\mathrm{ClO}_{4}}$ (Figs 2a and 2c). The incorporation of GO in the PNMA matrix was further confirmed with XPS measurements showing the presence of the peak centered at $286.8 \mathrm{eV}$ originating from C-O groups of GO (epoxy and alkoxy) (Fig. 3b) [8].

The PNMA- $\mathrm{ClO}_{4}-\mathrm{GO}$ films were exposed to electrochemical reduction in oxygen-free $0.1 \mathrm{M} \mathrm{KCl}$ at $-0.85 \mathrm{~V}$ (vs. $\mathrm{Ag} / \mathrm{AgCl} / 3 \mathrm{M} \mathrm{KCl}$ ) for 0,10 and 30 min to reduce $\mathrm{GO}$ to $\mathrm{rGO}$ in the PNMA matrix. The C 1s XPS spectra of the reduced films in Figs. 3b-3d show that most of the oxygen-containing surface groups of GO (hydroxyl, epoxy, carbonyl and carboxyl) were removed after $30 \mathrm{~min}$ reduction $(\mathrm{C}-\mathrm{C} / \mathrm{C}=\mathrm{C}: 284.7 \mathrm{eV}$; $\mathrm{C}-\mathrm{N}: 285.7 \mathrm{eV}$; C-OH/C-O-C: $286.8 \mathrm{eV}$; C=O: $288.1 \mathrm{eV}$; O=C-O: $289.4 \mathrm{eV}$ [6,8]). For comparison, the $\mathrm{C}$ 1s XPS spectrum

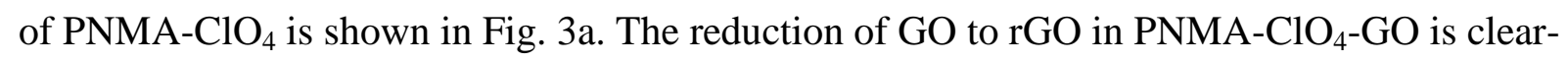
ly observed as a considerable decrease of the intensity of the XPS band at $286.8 \mathrm{eV}$. Simultaneously, the C:O ratio increased from 2.90 (unreduced film) to 4.04 and 4.71 for the films reduced for 10 and 30 min, respectively. Neither FTIR nor Raman spectroscopy could verify the reduction of GO to rGO because the PNMA bands strongly overlap with the GO and rGO bands [6].

The electrical conductivity of thin polymer films prepared on conducting substrates cannot be reliably measured. We therefore chose to investigate possible improvements in the electron transfer of the PNMA-ClO $4-$ rGO film in the presence of $\left[\mathrm{Ru}\left(\mathrm{NH}_{3}\right)_{6}\right] \mathrm{Cl}_{2}$. Another reduction approach was used in these studies to transform GO to rGO. First, the $\mathrm{PNMA}^{-\mathrm{ClO}_{4}-}$ 
GO film was electrochemically reduced in oxygen-free $0.1 \mathrm{M} \mathrm{KNO}_{3}$ for 10 min at $-0.94 \mathrm{~V}$ $[8,9]$. The $\mathrm{CVs}$ of the PNMA-ClO $4-\mathrm{GO}$ film before and after the electrochemical reduction showed that the composite film withstands the reduction without losing its electroactivity (Fig. 4a). After the reduction, CVs of the PNMA-ClO 4 , PNMA-ClO $4-\mathrm{GO}$ and $\mathrm{PNMA}_{4}-\mathrm{ClO}_{4}-\mathrm{rGO}$ films, and the glassy carbon (GC) substrate were recorded between $-0.6 \mathrm{~V}$ and $0.15 \mathrm{~V}$ in 0.1 $\mathrm{M} \mathrm{KNO}_{3}$ containing $2 \mathrm{mM}\left[\mathrm{Ru}\left(\mathrm{NH}_{3}\right)_{6}\right] \mathrm{Cl}_{2}$ (Fig. 4b). Before starting the potential cycling from $-0.6 \mathrm{~V}$, the potential was first held for $2 \mathrm{~min}$ at $-0.6 \mathrm{~V}$ to convert the PNMA matrix to the electrically non-conducting form. Fig. 4b (curve 1) show distinct oxidation and reduction peaks for the $\mathrm{Ru}\left(\mathrm{NH}_{3}\right)_{6}{ }^{2+/ 3+}$ redox couple on $\mathrm{GC}$ with the anodic and cathodic peak potentials at $\mathrm{E}_{\mathrm{p}, \mathrm{a}}=-0.102 \mathrm{~V}$ and $\mathrm{E}_{\mathrm{p}, \mathrm{c}}=-0.179 \mathrm{~V}$, respectively, indicating that the redox reaction is nearly reversible $\left(\Delta \mathrm{E}_{\mathrm{p}}=0.077 \mathrm{~V}\right)$. In contrast to $\mathrm{GC}$, much lower oxidation and reduction currents with higher peak potential separations were observed for the $\mathrm{PNMA}^{-\mathrm{ClO}_{4}}$ and $\mathrm{PNMA}^{-\mathrm{ClO}_{4}}$ GO films. Due to their almost non-conducting nature in the potential interval of Fig. $4 \mathrm{~b}$ (curves 2 and 3), the electron transfer at the solution-membrane interface and within the PNMA matrix is limited and sluggish resulting in low redox current and high peak separation.

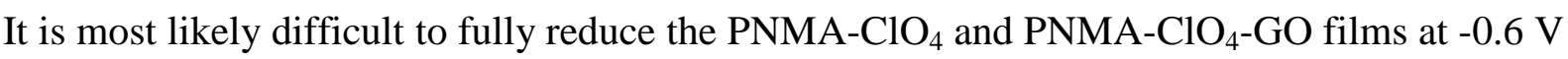
which is the reason for their slight redox activity. Moreover, the oxidation of these film matrices starts at ca $0.0 \mathrm{~V}$ (Fig. 1b) and consequently, it also slightly contributes to the redox currents observed at E > $0.0 \mathrm{~V}$ in Fig. $4 \mathrm{~b}$ (curves 2-4). However, after electrochemical reduction

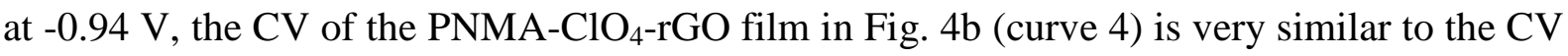
of GC showing almost reversible redox behavior and distinct oxidation and reduction peaks for the $\mathrm{Ru}\left(\mathrm{NH}_{3}\right)_{6}{ }^{2+/ 3+}$ redox couple $\left(\mathrm{E}_{\mathrm{p}, \mathrm{a}}=-0.07 \mathrm{~V}, \mathrm{E}_{\mathrm{p}, \mathrm{c}}=-0.20 \mathrm{~V}, \Delta \mathrm{E}_{\mathrm{p}}=0.13 \mathrm{~V}\right)$. This is in good accordance with the nearly reversible electron transfer kinetics for $\mathrm{Ru}\left(\mathrm{NH}_{3}\right)_{6}{ }^{3+}$ on single-layer

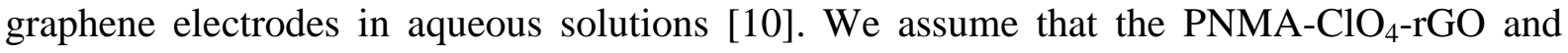
PNMA-ClO 4 -GO films have equal surface areas. Hence, the improved redox behavior of the 


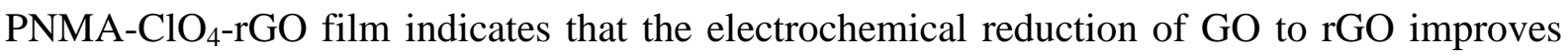
the electron transfer in the composite film.

In conclusion, we have shown that a composite film of rGO and PNMA with enhanced electron transfer can be prepared with a simple electrochemical procedure. It is expected that the composite film can be used, for example, as an ion-to-electron transduction layer in solidstate chemical sensors operating at neutral $\mathrm{pH}$ which is usually unsuitable for most PANIs.

\section{REFERENCES}

[1] MacDiarmid AG, Chiang JC, Richter AF. Polyaniline: A new concept in conducting polymers. Synth Met 1987; 18:285-290.

[2] Lindfors T, Ivaska A. pH sensitivity of polyaniline and its substituted derivatives. J Electroanal Chem 2002; 531:43-52.

[3] Sivakumar R, Saraswathi R. Redox properties of poly( $N$-methylaniline). Synth Met 2003; 138(3):381-390.

[4] Lindfors T, Ivaska A. Potentiometric and UV-vis characterization of $N$-substituted polyanilines. J Electroanal Chem 2002; 535:65-74.

[5] Watanabe A, Mori K, Iwabuchi A, Iwasaki Y, Nakamura Y. Electrochemical polymerization of aniline and $N$-alkylanilines. Macromolecules 1989; 22:3521-3525.

[6] Österholm A, Lindfors T, Kauppila J, Damlin P, Kvarnström C. Electrochemical incorporation of graphene oxide into conducting polymer films. Electrochim Acta 2012; 83:463-470. [7] Bai H, Xu Y, Zhao L, Li C, Shi G. Non-covalent functionalization of graphene sheets by sulfonated polyaniline. Chem Commun 2009;1667-1669.

[8] Lindfors T, Österholm A, Kauppila J, Pesonen M. Electrochemical reduction of graphene oxide in electrically conducting poly(3,4-ethylenedioxythiophene) composite films. Electrochim Acta 2013;DOI: 10.1016/j.electacta.2013.03.070. 
[9] Ramesha KR, Srinivasan S, Electrochemical reduction of oriented graphene oxide films: An in situ Raman spectroelectrochemical study. J Phys Chem C 2009; 113(19):7985-7989. [10] Ritzert NL, Rodríguez-López J, Tan C, Abruña HD. Kinetics of interfacial electron transfer at single-layer graphene electrodes in aqueous and nonaqueous solutions. Langmuir 2013; 29:1683-1694.

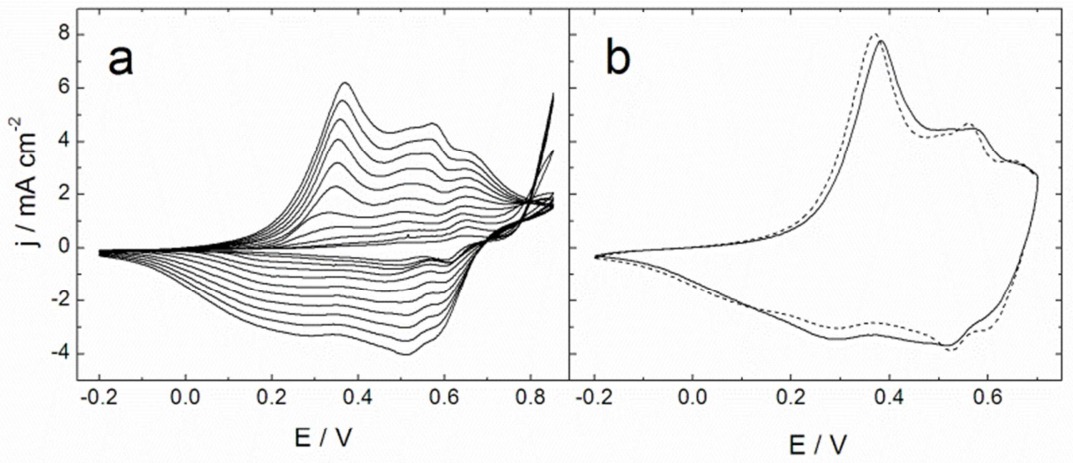

Fig. 1. (a) Electropolymerization of $N$-methylaniline with cyclic voltammetry in an aqueous solution consisting of graphene oxide $(4.4 \mathrm{mg} / \mathrm{ml})$ and $1.0 \mathrm{M} \mathrm{HClO}_{4}$. Every $5^{\text {th }}$ cycle of total

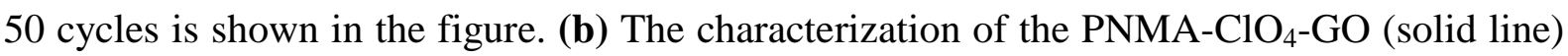
and the $\mathrm{PNMA}_{-} \mathrm{ClO}_{4}$ (dashed line) films in monomer-free $1.0 \mathrm{M} \mathrm{HClO}_{4}$. In (a) and (b): RE: $\mathrm{Ag} / \mathrm{AgCl} / 3 \mathrm{M} \mathrm{KCl}, \mathrm{v}=50 \mathrm{mV} / \mathrm{s}$. 


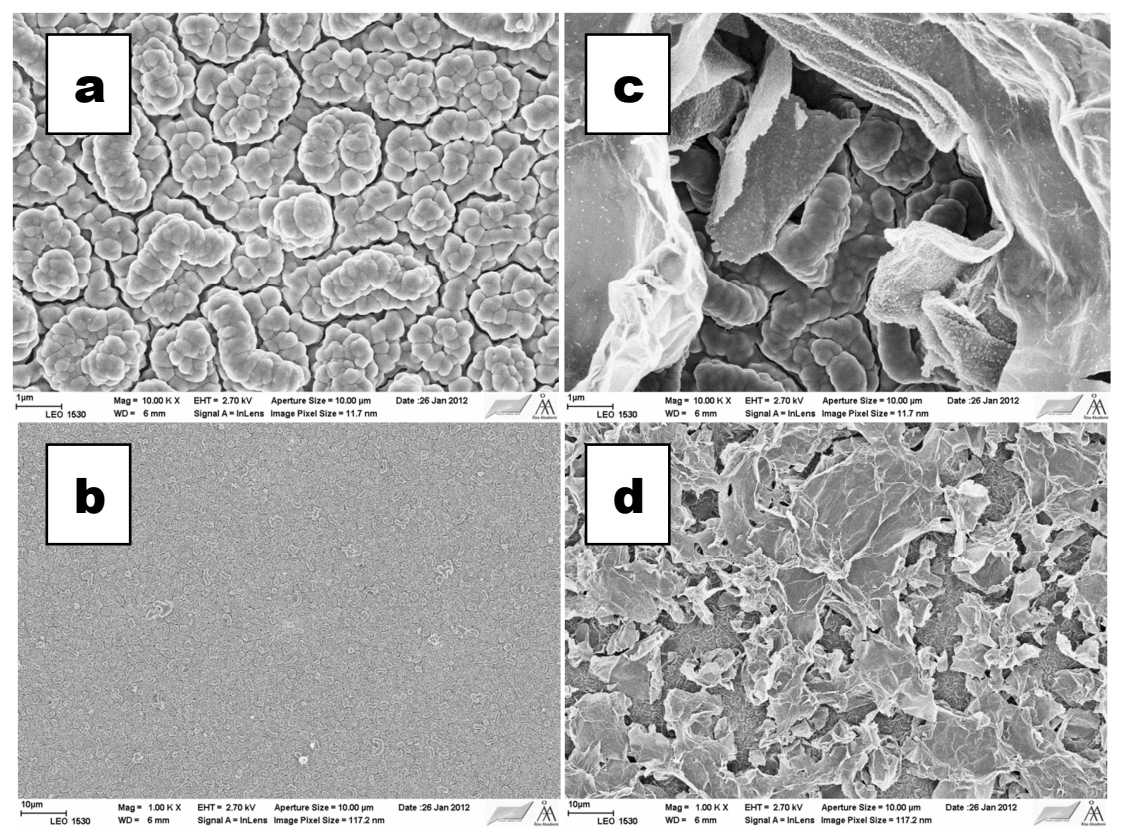

Fig. 2. SEM images of $(\mathbf{a}, \mathbf{b})$ the $\mathrm{PNMA}_{-} \mathrm{ClO}_{4}$ and $(\mathbf{c}, \mathbf{d})$ the $\mathrm{PNMA}-\mathrm{ClO}_{4}-\mathrm{GO}$ films. Magnifications: $10000 \mathrm{x}(\mathrm{a}, \mathrm{c})$ and $1000 \mathrm{x}(\mathrm{b}, \mathrm{d})$.

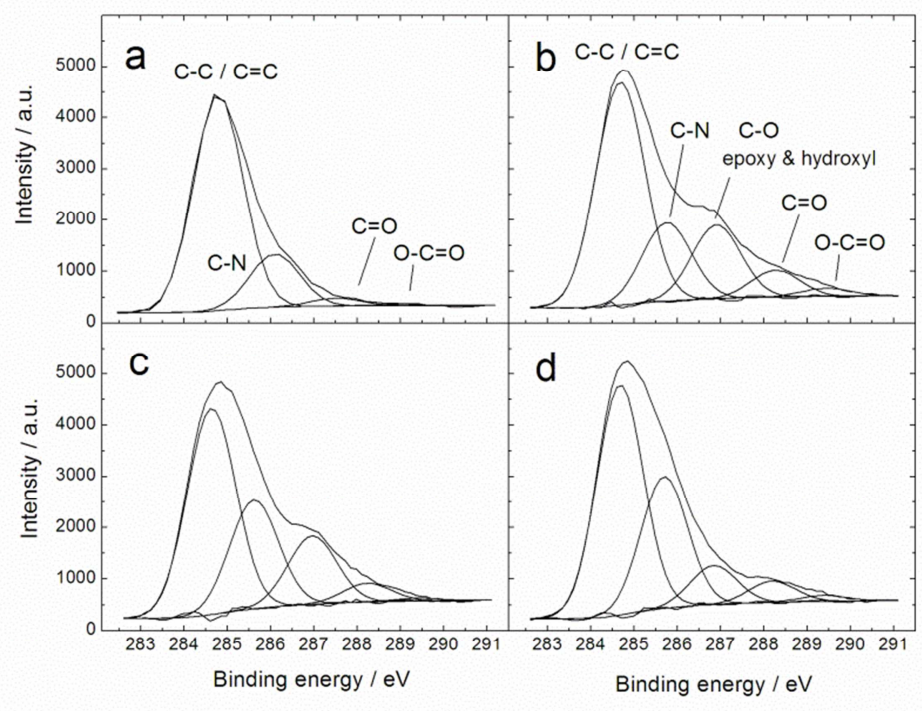

Fig. 3. $\mathrm{C} 1 \mathrm{~s}$ XPS spectra of (a) the PNMA-ClO 4 film $\left(\chi^{2}=5.16\right)$ and (b-d) the $\mathrm{PNMA}^{-\mathrm{ClO}_{4}-}$ GO films which were electrochemically reduced in $0.1 \mathrm{M} \mathrm{KCl}$ at $-0.85 \mathrm{~V}$ (vs. $\mathrm{Ag} / \mathrm{AgCl} / 3 \mathrm{M}$ $\mathrm{KCl})$ for (b) $0 \min \left(\chi^{2}=2.48\right)$, (c) $10 \min \left(\chi^{2}=4.11\right)$ and (d) $30 \min \left(\chi^{2}=3.17\right)$. 


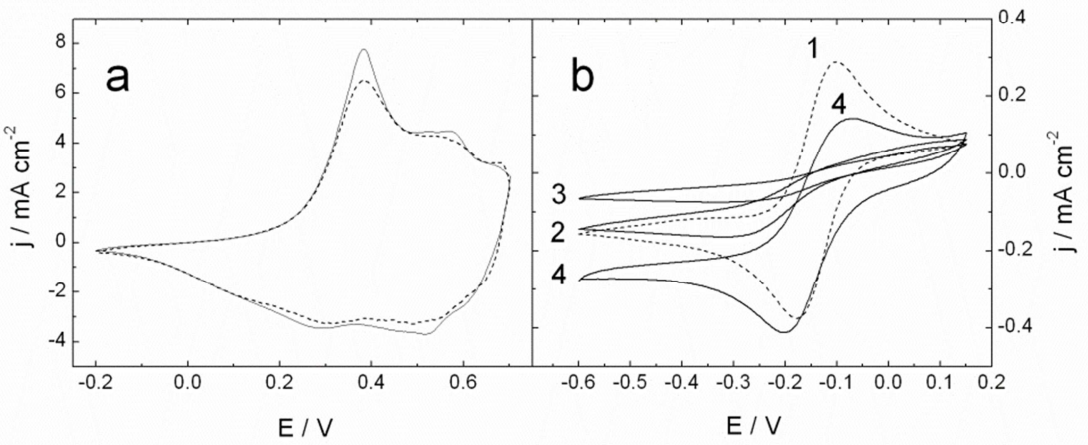

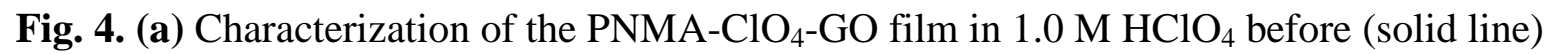
and after (dashed line) electrochemical reduction for $10 \mathrm{~min}$ in $0.1 \mathrm{M} \mathrm{KNO}_{3}$ at $-0.94 \mathrm{~V}$. (b) CVs of the (1) GC substrate, (2) PNMA-ClO

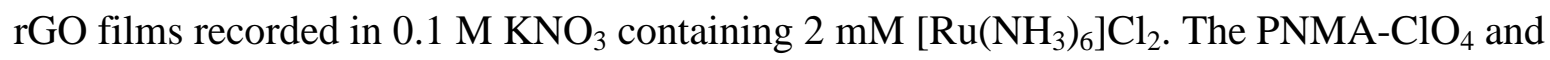
the PNMA-ClO 4 -rGO films were first electrochemically reduced for 10 min in $0.1 \mathrm{M} \mathrm{KNO}_{3}$ at $-0.94 \mathrm{~V}$ prior to the measurements. The films were held at $-0.60 \mathrm{~V}$ for $2 \mathrm{~min}$ before recording the CVs. In (a) and (b): $\mathrm{RE}: \mathrm{Ag} / \mathrm{AgCl} / 3 \mathrm{M} \mathrm{KCl}, \mathrm{v}=50 \mathrm{mV} / \mathrm{s}$. 